\title{
Comparative evaluation of RT-PCR with sandwich-ELISA for detection of Peste des petits ruminant in sheep and goats
}

\author{
Sumit Mahajan ${ }^{1}$, Rajesh Agrawal ${ }^{2}$, Mahesh Kumar $^{3}$, Anand Mohan ${ }^{4}$ and Nishi Pande ${ }^{5}$ \\ 1. Division of Medicine, Indian Veterinary Research Institute (IVRI), Izatnagar, Bareilly (U.P), India; \\ 2. Division of Veterinary Epidemiology and Preventive Medicine, F.V.SC \& AH, SKUAST-J ammu, J\&K, India; \\ 3. Department of Epidemiology and Preventive Medicine, C.V.A.Sc., GBPUA\&T, Pantnagar, Uttrakhand, India; \\ 4. Dvision of B\&M, Indian veterinary Research Institute, Izatnagar, Bareilly (UP); \\ 5. Division of Animal Reproduction Gynecology and Obstetrics, F.V.Sc \& AH, SKUAST-J ammu, J\&K, India. \\ Corresponding author: Sumit Mahajan, email:sumit22_mahajan@rediffmail.com \\ Received: 26-08-2012, Accepted: 04-10-2012, Published online: 25-02-2013
}

How to cite this article: Mahajan S, Agrawal R, Kumar M, Mohan A and Pande N (2013) Comparative evaluation of RT-PCR with sandwich-ELISA for detection of Peste des petits ruminant in sheep and goats, Vet. World 6(6):288-290, doi: 10.5455/ vetworld.2013.288-290

\begin{abstract}
Aim: To assess the suitability, sensitivity and specificity of F gene based RT-PCR for detection of PPRV infection in India.

Materials and Methods: A total of 26 blood samples collected from 26 animals suspected for Peste des petits ruminant (PPR) were tested by RT- PCR using F1/F2 primers set and then compared with sandwich-ELISA for detection of PPR virus.

Results: Out of 26 samples tested RT-PCR reported 10 (38.46\%) samples as positive as compared to Sandwich-ELISA which reported 11(42.30\%) samples as positive for PPR virus. Further analysis of samples revealed that $3(11.53 \%)$ samples which were negative by sandwich-ELISA reported positive with RT-PCR. Whereas 4 (15.38\%) samples shown negative by RT-PCR were positive with sandwich-ELISA. The relative sensitivity and specificity of F-gene based RT-PCR when compared with sandwich-ELISA was $63.60 \%$ and $80.00 \%$, respectively. The overall agreement between the two tests was of $73.10 \%$ with kappa value 0.442 , which suggesting a moderate agreement between the two tests.

Conclusion: A low sensitivity and specificity along with moderate agreement shown by F- gene based RT-PCR when compared with sandwich ELISA suggests that some other highly sensitive and specific primers should be explored for detection of PPR by RT-PCR.
\end{abstract}

Keywords: evaluation, Peste des petits ruminant (PPR), RT- PCR, sandwich-ELISA.

\section{I ntroduction}

Peste des petits ruminant (PPR), which literally means "Plague of small ruminants", causes high morbidity and mortality in susceptible sheep and goats [1]. The disease is caused by a Morbillivirus which is closely related to canine distemper, rinderpest and measles viruses [2] that cause some of the most devastating viral diseases of humans and animals worldwide [3]. The virus can be genetically grouped into four distinct lineages (I, II, III, and IV) based on partial fusion protein $(\mathrm{F})$ or nucleoprotein $(\mathrm{N})$ gene sequence analysis. All four lineages have now been detected in Africa whilst only lineage IV appears to be circulating across Asia [4-6].

In India, the disease was first reported in 1987 from the village Arasur of Tamil Nadu [7] and since then, it has become endemic in India [1,5,8]. Economic losses due to PPR have been estimated to be 1800 million Indian rupees annualy and presently this disease is considered as one of the major threats to small ruminant population of the country [9]. A reverse transcription polymerase chain reaction (RT-PCR) technique using F-gene primers developed by Forsyth

This article is an open access article licensed under the terms of the Creative Commons Attribution License (http://creativecommons. org/licenses/by/2.0) which permits unrestricted use, distribution and reproduction in any medium, provided the work is properly cited. and Barett [10] has been the most popular and highly sensitive tool for diagnosis of PPR. But couple of recent studies revealed that, the widely used $\mathrm{F}$ gene basedRT- PCR technique failed to detect PPR virus from few of the samples that had been tested positive by sandwich ELISA [11-13]. Kerur et al. [14] also reported that newly designed N-gene based RT-PCR detected PPR virus in a greater number of samples than $\mathrm{F}$ gene based RT-PCR developed by Frosyth and Barett. Both Tiwari [12] and Kerur [13] in their respective studies showed that different clinical samples of PPR taken from same animals had shown uneven results by F gene based RT-PCR for detection of PPRV antigen. Keeping in view the results of recent studies a need was felt to assess the suitability, sensitivity and specificity of F gene based RT-PCR which are currently in uses for detection of PPR virus infection in India.

\section{Materials and Methods}

Detection of PPR virus by RT-PCR: For RT-PCR, Total RNA from whole blood samples was extracted by using PureLink ${ }^{\mathrm{TM}}$ Total RNA Blood Purification Kit from Invitrogen life technologies, USA (Cat no K1560-01), strictly according to the manufacturer instruction. RNA with acceptable purity was then amplified by using GeNei One Step AMV RT-PCR Kit. 
Table - 1 Comparative evaluation of F- gene based RT-PCR with Sandwich ELISA in detection of PPRV antigen in clinical samples

\begin{tabular}{llc}
\hline Sr. no. & Parameters & $\begin{array}{r}\text { Gold standard:- Sandwich ELISA } \\
\mathrm{a}=7, \mathrm{~b}=3, \mathrm{c}=4, \mathrm{~d}=12\end{array}$ \\
\hline 1 & Sensitivity & $63.60 \%$ \\
2 & Specificity & $80 \%$ \\
3 & Positive predictive value & 0.700 \\
4 & Negative predictive value & 0.750 \\
5 & Overall fraction correct & 0.731 \\
6 & Positive Likelihood Ratio & 3.182 \\
7 & Negative Likelihood Ratio & 0.455 \\
8 & Diagnostic Odds & 7 \\
9 & Error Odds Ratio & 0.437 \\
11 & Kappa value & 0.442 \\
12 & Overall agreement & $73.10 \%$ \\
\hline
\end{tabular}

$a=$ Samples positive to both conventional and the gold standard tests, $b=$ Samples positive to conventional but negative to the gold standard test, $\mathrm{C}=$ Samples negative to conventional but positive to the gold standard test, $d=$ samples negative to both conventional and the gold

Mastermix was prepared as per manufacture instruction. PCR amplification was carried out by using $\mathrm{F}$ gene-specific primers $\mathrm{F} 1$ and F2 [10] amplifying $372 \mathrm{bp}$ product. Reaction master mix I contain; RNasin, GeNei ${ }^{\mathrm{TM}}$ 2X RT PCR reaction mix, $\mathrm{GeNe}^{\mathrm{TM}} \mathrm{RT}-\mathrm{PCR}$ enzyme mix and primers with final concentration of $0.6 \mu \mathrm{M}$ was prepared in separate 0.2 $\mathrm{ml}$ tube. Whereas master mix II containing template RNA was taken in separate $0.2 \mathrm{ml}$ PCR tubes and heated at $65^{\circ} \mathrm{C}$ for 5 minutes in water bath to denature the template RNA and then chilled on ice before adding it to the Master Mix I. These PCR tubes were then placed in thermocycler and reverse transcription was done at $50^{\circ} \mathrm{C}$ for $30 \mathrm{~min}$ followed by 35 PCR cycles. The reaction conditions for F1/F2 primers were kept similar to that described by Forsyth and Barett [10].

Ten microliters of the PCR products were resolved on a $2 \%$ agarose gel stained with $0.5 \mu \mathrm{l} / \mathrm{ml}$ ethidium bromide and electrophoresed at $75 \mathrm{~V}$ for 30 min in $0.5 \mathrm{X}$ TBE buffer. The amplified product was visualized as a single compact band of expected size under UV light and documented by gel documentation system (Alphaimager, Alphainnotech, Taiwan).

Detection of PPR virus by Sandwich ELISA: PPR sandwich-ELISA kit for PPR virus detection along with the user manual was obtained from Rinderpest Laboratory, Division of Virology, IVRI, Mukteswar. The test was performed strictly as per the protocol outlined in the user manual. The ELISA plates showing proper colour development in control wells were read at $492 \mathrm{~nm}$ in ELISA plate reader (Multiskan plus, LabSystem).

For calculation of cut off point, four antigen blank wells having extreme optical density (OD) values (two wells each of lowest and highest OD values) were excluded. The remaining four wells having intermediate OD values were considered and the cut off was taken as two times the mean OD of these intermediate wells. Samples having more OD than the cut off were taken as positive, while samples having

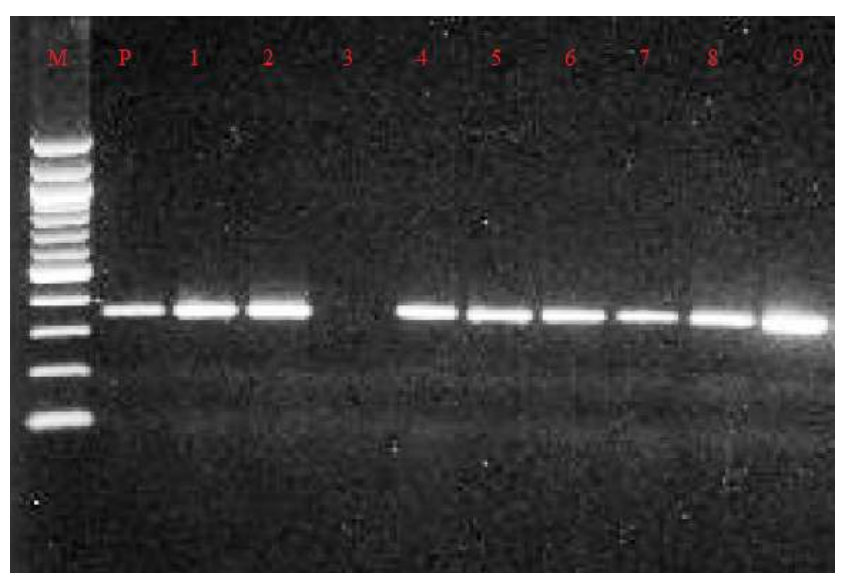

Figure-1. Agarose gel electrophoresis of 372 bp PCR product amplified by F1/F2 primers

M-100 bp Marker, 1245678 9- Positive samples, P- Positive control, 3 Negative sample

less OD than the cut off were taken as negative. Further, a sample positive in one well and negative in other duplicate well was retested before recording the results.

Statistical analysis: The sensitivity and specificity of the RT-PCR, along with positive and negative predictive values, Kappa statistics ( $\kappa$ ) was analyzed by using online statistical program [15].

\section{Results and Discussion}

In the present study, F-gene based RT-PCR was compared parallel to sandwich-ELISA for evaluation of diagnostic sensitivity and specificity of F-gene based RT-PCR for detection of PPR virus antigen. In the present study it was observed that out of 26 samples tested RT-PCR reported $10(38.46 \%)$ samples as positive as compared to Sandwich-ELISA which reported $11(42.30 \%$ ) samples as positive for PPR virus. Further analysis of samples revealed that 4 (15.38\%) samples shown negative by RT-PCR were shown positive with sandwich-ELISA whereas $3(11.53 \%)$ samples which were negative by sandwich-ELISA reported positive with RT-PCR. Whereas both the tests were in agreement with each other showing $26.92 \%$ samples as positive and $46.15 \%$ samples as negative respectively. The results are in agreement with Chauhan et al. [16] who reported that some of the samples positive by sandwich ELISA were found negative by RT-PCR.

Sensitivity and specificity of RT-PCR was $63.60 \%$ and $80.00 \%$, respectively when compared with sandwich-ELISA (assuming sandwich ELISA as gold standard). The overall fraction correct value or accuracy of F-gene based RT-PCR was 0.731, with an overall agreement between the two tests of $73.10 \%$, further supported by kappa value of 0.442 suggesting a moderate agreement between the two tests. The results are in agreement with Kerur [13] who reported sensitivity and specificity of RT-PCR was $60.60 \%$ and $73.33 \%$, respectively. Further lower sensitivity of RT- 
PCR to sandwich-ELISA was observed by George [11] and Tiwari [12] i.e. 12.50 and $53.33 \%$, respectively. However, the specificity was $100 \%$ in their studies, using the sameF1-F2 primer pair for PPR virus detection.

The lower relative sensitivity observed with RTPCR might be ascribed to genome organization of the PPR virus, which results in higher rate of transcription of $\mathrm{N}$-gene as compared to the F-gene. Thus, the abundance of nucleoprotein which is targeted in sandwich-ELISA may result in relatively higher sensitivity of the ELISA as compared to F-gene based RT-PCR [11,13]. Several other factors also affect the success of reverse transcription step and appear to be crucial in RT-PCR affecting its sensitivity. RNase contamination of RNA samples could also result in apparently lower sensitivity of RT-PCR due to failure of reverse transcription step, especially when RNA concentration in sample is low $[12,15]$. Thus, less sensitivity observed in present study than, might possibly be due to the fact that supplementation of RNase inhibitor was not done during the transcription reaction in the present study. Further, mutations in the primers target region on virus genome may negate the effectiveness of primers and also the nucleic acid amplification techniques like RT-PCR was not able to identify subviral components such as empty virions, which may be produced late in an infection leading to lower sensitivity of RT-PCR.

\section{Conclusion}

A low sensitivity and specificity along with moderate agreement shown by F- gene based RT-PCR when compared with sandwich ELISA suggests that some other highly sensitive and specific primers should be explored for detection of PPR by RT-PCR.

\section{Authors' contribution}

SM, RA and MK planned and designed the study. SM collected samples from field. AM and SM analysed sample in laboratory. MK and NP did statistical analysis and compiled data. All authors drafted, revised and approved the final manuscript.

\section{Acknowledgements}

Authors are grateful to Veterinary Assistant Surgeon, migratory sheep and goat project, Department of Sheep husbandry, Jammu for providing help during sampling and Head Department of Epidemiology and Preventive Medicine, Veterinary College, GBPUA\&TPantnagar for providing necessary faculties and timely help to carry out the research work and Head Division of Virology, IVRI for providing ELISA kit and PPR vaccine virus.

\section{Competing interests}

Authors declare that they have no competing interests.

\section{References}

1. Singh, R.P. (2011) Control strategies for Peste des petits ruminants in small ruminants of India, Rev. Sci. Tech. 30 (3): 879-887.

2. Van mol, P., Alldinger, S., Baumgartner, W. and Admi, M. (1995) Distemper in wild carnivores: An epidemiological, histological and immunochemical study, Vet. Microbiol., 44: 193-199.

3. Misbah, A., Muhammad, A., Anjum, R., Shamim, S. and Ali, Q. (2009) Prevalence of Peste Des Petits Ruminants Virus (PPRV) in Mardan, Hangu and Kohat District of Pakistan; Comparative Analysis of PPRV Suspected serum samples using Competitive ELISA (cELISA) and Agar Gel Immunodiffusion (AGID), Vet. World, 2(3): 89-92.

4. Banyard, A.C., Parida, S., Batten, C., Oura, C., Kwiatek, O. and Libeau, G. (2010) Global distribution of peste des petits ruminants virus and prospects for improved diagnosis and control, J. Gen. Virol., 91: 2885-2897.

5. Singh, R.K., Balamurugan, V., Bhanuprakash, V., Sen, A., Saravan, P., and Yadav, M.P. (2009) Possible control and eradication of peste des petits ruminants from India: technical aspect, Vet. Ital., 45(3): 449-462.

6. Chauhan, H.C., Chandel, B.S., Kher, H.N., Dadawala, A.I. and Agrawal, S. M. (2009) Pesti des petits ruminant's virus infection in animals, Vet. World, 2(4):150-155.

7. Shaila, M.S., Purashothaman, V., Bhavsar, D., Venugopal, K. and Venkatesan, R.A. (1989) Peste des petits ruminants of sheep in India, Vet. Rec., 125: 602.

8. Mahajan, S., Agrawal, R., Kumar, M., Mohan, A. and Pande, N. (2012) Risk of seroconversion to peste des petits ruminants (PPR) and its association with species, sex, age and migration, Small Rum. Res., 104: 195-200.

9. Bhadyopadhyay, S.K. (2002) The economic appraisal of a PPR control programme in India. In 14th annual conference and national seminar on managememt of viral diseases with emphasis on global trade and WTO regime, Indian virology society, 18-20 January, Hebbal Banglore. Indian virology society, Hisar.

10. Forsyth, M. and Barrett, T. (1995) Detection and differentiation of rinderpest and peste des petits ruminants viruses in diagnostic and experimental samples by polymerase chain reaction using $\mathrm{P}$ and $\mathrm{F}$ gene-specific primers, Virus Res., 39: 151-163.

11. George, A. A. (2002) Comparative evaluation of different gene targets for PCR diagnosis of PPR. M.V.Sc. thesis. Deemed University IVRI, Izatnagar, India.

12. Tiwari, A. (2004) Prevalence of Peste des petits ruminants (PPR) virus in small ruminants of Gujarat and its characterization by RT-PCR/ RFLP and SSCP profiles. M.V.Sc. thesis, Anand Agricultural University, Anand, India.

13. Kerur, N. (2005) Assessment of different gene targets for detection of Peste des petits ruminants virus by RT-PCR and sequence analysis of $\mathrm{F}$ and $\mathrm{N}$ gene segments. M.V.Sc. thesis, Anand Agricultural University, Anand, India.

14. Kerur, N., Jhala, M.K. and Joshi C.G. (2008) Genetic characterization of Indian peste des petits ruminants virus (PPRV) by sequencing and phylogenetic analysis of fusion protein and nucleoprotein gene segments, Res. Vet. Sci., 85: $176-183.1$

15. 2-way Contingency Table Analysis., In http://statpages. org/ctab2x2.html. Retrieved on 20/07/10.

16. Chauhan, H.C., Kher, H.N., Dadawala, A.I., Kumar, P., Sen, A., Chandel, B.S. (2012) Detection of Peste des petits ruminants virus in sheep and goats, Indian Vet. J., 89(8): 6062. 